youngest patient, so far as the recorded cases at present stand, was sixteen, the oldest seventy.two. In the matter of etiology there is little to be said. In the majority of cases the trouble, as in the present instance, appeared without apparent cause. In a few examples the cyst made its appearance within a comparatively short time of the rreceipt of an injury. In one case at least the trouble seems to have followed an attack of " acu te gastro-enteritis." In the majority of cases the symptoms, apart from the appearance of the growth, have been almost negative. The tumour has usually increased rapidly, and the chief complaints have been of a painful sense of fulness after food, of distension, of digestive disturbances, and possibly of nausea. Eructations are common, and the patients are usually described as languid, feeble, or depressed. Emaciation to any extent is seldom present; vomiting is comparatively rare. In Dr. Bull's case there was bæmorrbage from the stomach and bowel. The pain complained of has usually soen slight and of a vague neuralgic character. The appearance of the cyst has been preceded by periodic attacks of pain or by a long-standing sense of discomfort in the -epigastrium. The bowels have in most of the examples acted regularly. Diarrhoa is mentioned in many instances, but in no case do fatty stools appear to have been passed. Albumen or sugar in the urine is noted in not a few examples. There is no ascites, and, as a rule, no jaundice. 'The skin is usually described as dusky, dirty, earthy, unhealthy looking, or yellowish. The tumour is round and tense. It is elastic and may not give a sense of fluctuation. it is of clear outline, often presents aortic impulse, but is usually not movable. Adhesions are quite uncommon. It is situated above the umbilicus in the epirastric region. It may be in close contact with the liver; it nay be large enough to fill the whole abdomen. The fluid is usually turbid, brownish, odourless, and of fairly bigh specific gravity. It is alkaline or neutral in reaction, contains albumen, but neither bile nor urea. It has the power of emulsifying fat and of converting starch into sugar. In many cases it has caused the skin about the wound to be "very sore and raw, and it has been described as "digesting the skin." The brownish colour of the fluid is due to an admixture of blood, and in the rarer cases the fluid has exhibited lighter tints, and has been described as yellow, and even as white. It appears to be always turbil. It may possess no digestive properties, just as the fluid in hydrotnephrosis may possess few, if any, of the specific features of arine.

When Senn's paper was written, in no instance had a correct diagnosis been made before operation. Since that wime, however, the nature of the affection has been recognised by many, by Lardy, Subotic, Wöltier, Bull, and thers In not a few cases an exploratory tapping has not enabled the surgeon to make a sure diagnosis. Pancreatic cysts have been mistaken for ovarian tumour, hydatid cyst, imalignant growths, lipoma, circumseribed peritonitis, and even aneurysm. Senn's statement, that "a positive diagnosis af a cyst of the pancreas is impossible," must now be modified, and with the knowledge we now possess there is uno reason why the condition should not, in all uncomplicated cases, be recognised. The disease, if left to itself, appears to be always fatal, and I believe nothing is known of any mode of spontaneous cure.

In the matter of treatment, I have collected twenty-four examples of cyst of the pancreas treated by operation. They may be thus arranged :-

$$
\begin{aligned}
& \text { No. of cases. Recoveries. Death } \\
& \text { Removal or attempted re- } \\
& \text { moval } \\
& \text { simple tapping ................ } \\
& \begin{array}{rrrrrr}
16 & \ldots \ldots \ldots & 15 & \ldots \ldots \ldots & 1 \\
6 & \ldots \ldots \ldots & 1 & \ldots \ldots \ldots & 5 \\
2 & \ldots \ldots \ldots & - & \ldots \ldots \ldots & 2 \\
\hline 24 & & - & & \frac{2}{8}
\end{array}
\end{aligned}
$$

It must be understood that in those who recovered a anstula was left which was in some cases many months in closing. The possibility of a permanent fistula may be disregarded. Among the cases of recovery is Dr. Bull's case. The patient survived the operation, and may be said to Thave entirely recovered from it when he died of diabetes. The figures given above show very conclusively that the line of treatment should be by incision and drainage, and that no attempt should be made to remove the cyst. The treatment by repeated tapping has nothing to recommend itt, and an exploratory tapping is also to be condemned.
Litorature.-The following are the papers upon which the above observations are founded :- Salzer: Zeitschrift fuir Hcillutende, Bd. vii. Kootz: "Inaug. Diss.," Marburg, 1886. Kuister: Berliner Klin. Woohens., 188 7 , No. 9. Subotic: Wiener Med. Zcitung, 1887, No. 23. Bull : Nevo York Med. Jour., vol. xlvi., p. 376. Nicholls : New York Med. Jour., vol. xlvii., p. 575. Kühnast: "Dissert.," Breslau, 1887 (forty-five examples). Lardy : Korrespon. denzblatt fur Schveizer Aerzte, 1888. Wïllier: Zcitschrift für Itcilkuncle, Bd. ix., p. 119 (diagnosis made before operation in the case of a femalc aged twenty-one). Tremaine : Trans. Amer. Surg. Assoc, 1898, p. 557. Fenger and Steele: Chickryo Med. Jour, April and May, 1888 . Annandale: Brit. Witd. Jour, June 8th, 18s9. The following monographs which bear indirectly on the subject may also be mentioned:-Hagenbach : Ieutsche Zeitschrift für Chirurgie, 13d. xxvii., p. 110. Martinotti : Centralblatt fir Chirurgis (abstract), 1889, p. 141. At the time that this lecture was given I was not aware that a case of pancreatic cyst had been operated upon in this country. Professor Annandale's case was not published until 188?, although operated upon early in 1885. The operation was perfectly successful. Mr. (\%. Smith, in his work on "Abdominal Surgery," alludes to an unpublished case operated upon by Professor Ogston. Other cases have no doubt been met with and operated upon, although the details have not been placed on record. The literature of the last few years would appear to show that cyst of the pancreas is a less rare affection than was at one time supposed.

\section{ON GASTRIC ULCER AND ITS TREATMENT BY ENEMATA.}

BY H. B. DONKIN, M B. Oxon., F.R.C.P., PIISSICIAN to WESTMINSTER Mospitil.

A CAREFUL study of the clinical symptoms and postmortem facts of round ulcer of the stomach forces one to acknowledge that oftentimes the diagnosis is a matter of doubt. The first symptom of such a gastric ulcer is sometimes that of perforation, unheralded by any complaint which points to stomach disorder. Two instances of this I have seen and examined post mortem where death followed in the one case in ten hours, and in the other in two days, on the first sign of any illness. And on the other hand, it is well known that healed gastric ulcers are seen at necropsies in cases where there is no history of any marked attack of the usual symptoms of the disease. Diagnosis is therefore liable to error both on the side of excess and of defect: the latter may lead us into serious mistakes, while the former is as harmless as it is of ten unavoidable. From a considerable experience and thought over such cases I feel sure that it is always wise to recognise in every protracted case of localised and unerrant pain after food continuing for any length of time, and especially when followed and reliered by vomiting, a possible gastric ulcer. Himatemesis clinches the diagnosis as a rule, after the exclusion, of course, as far as possible, of other primary and secondary morbid conditions of the stomach; but as a matter of safe practice it must not be looked upon as necessary for the diagnosis of the disease. We err on the safe side, if we err at all, in thus construing as liberally as possible the symptomatology of gastric ulcer. Doubtless there will be many cases in the remembrance of all experienced clinicians where much difficulty has been found in making the diagnosis between gastric ulcer and marked anæmia with abdominal neurosis, especially epigastric tenderness. But when such doubt exists, it is well, at least for a time, to treat the case as one of ulcer, in spite of such treatment being most inappropriate to the alternative condition. At the worst, but a litrle time is lost, which can soon be made up for when the diaynosis becomes clearer by instituting a vigorous course of tonic and nutritive treatmient and abandoning local measures. I am well assured that by avoidance of all food given by the month, thus keeping the stomach empty and restful, is much the shortest way of relieviner, and, in some cases, curing gastric ulcer. In instances where the diagnosis is certain and the symptom of hiomatemesis recent, I now begin at once with this line of treatment, and give the patient small enemata of milk and beef-tea at short jutervals; and in 
other instances, where the diagnosis may not be clear, I employ the same method when there is the slimhtest discomfort produred by the oral ingestion of small quantities of these fluids The time thus saved in the cure of these cases is remarkable when compared with the method so frequently followed of persisting with small quantities of fluid food by the mouth and the administration of sedatives, such as bismuth, opium, \&e. Many a case of so called "clironic dyspepsia," whatever that may mean, has been successfully treated in this manner, and I would take the opportunity to remark in passing that there is perhaps no more erroneous and misleading term in medical use than this same "chronic dyspepsia"; for, apart from the many cases of gastric uneasiness or pain which are clearly referable by a careful physician to general neurotic disorder, cases of chronic indigestion, instead of overfilling our out-patient rooms, as is so frequently and ignorantly reiterated, are rare indeed. The main object of this paper is to call attention to this matter of feeding by enemata in cases of gastric ulcer. As a partial basis for a short comment I subjoin abstracts of some cases of almost indubitable gastric ulcer treated in this manner. For these I am indebted to the labour of Dr. Wills, who out of a large number of more or less questionable cases in my wards during periods amounting to five years has extracted nearly all the definite ones, with the exception of some who died from hæmorrhage or perforation before any regular line of treatment could be instituted.

CASE 1.-Marie $\mathrm{H}-$, aged nineteen, kitchenmaid, was admitted to hospital on Oct. 10th, 1883 , with a history of marked pain after food, and sickness for some weeks, and hæmatemesis (half a pint) on Oct. 5th. For four days she had small quantities of milk and beef-tea by the mouth, slight hæmatemesis continuing. She was then put on small enemata of milk, peptones, and brandy, with ten minims of laudanum every four hours. For nineteen days, with one short interval of pain and hematemesis, she continued this treatment, and on the twentieth day was given some milk and a little bread-and-butter. She left the hospital on the fortieth day quite well, having for a week before discharge had ordinary diet.

CASE 2 -Florence $\mathrm{H}-$, aged twenty-four, was admitted to hospital on Nov. 6th, 1883. History of pain after food for two years, with three attacks of hæmatemesis and melæna, the last six months ago. She had been losing flesh considerably, and had derived no benefit from six months' out-patient treatment. She was placed on enemata of beef-tea and milk alternately, two ounces and a half every three hours, with half an ounce of brandy. She had ice to suck. On the thirteenth day a little milk was given by the mouth, and on the twenty-sixth the enemata were left off. She had been for nearly the whole time free from all symptoms. For a few days she had solid food without pain, but had to leave the hospital on the twenty-ninth day from admission on account of scarlet fever.

CASE 3.-Louisa $\mathrm{K}-$, aged twenty-three, housemaid, was admitted to hospital on Dec. 7 th, 1886 . One month's history of pain and vomiting after food, with hrematemesis on one occasion (a pint and a half). She lived on milk and puddings, but the pain and vomiting continued. For eleven days after admission she had enemata of milk, three ounces every two hours. Then she had milk and beeftea alternately every two hours (four ounces) by the mouth. On the twenty-fourth day she had solid food. No pain or vomiting after admission. Discharged well after thirtyeight days.

CASE 4.-Mary $\mathrm{H}-$, aged twenty-two, lady's maid, was admitted to bospital on Jan. $19 \mathrm{th}, 1887$, much wasted. History, five years pain, and some years vorniting after food; much worse last six months. Hrematemesis (one ounce) three weeks before admission. For the first three days she had small quantities of milk by the mouth; she had pain and vomited on the third day, and was then put on an enemata of two ounces of milk and one ounce of beef-tea every three hours, with a little ice to suck, and an injection of morphia, one-third of a grain, every night for the pain. The sickness diminished, but did not cease for six days. On the thirteenth day of treatment the enemata were reduced to four a day, two onnces of milk being given by the mouth every six hours alternately with the enemata. On the eighteenth day pnemata were s'opped, two ounces of milk in one ounce of bef $f$ tea being given every three hours. She was discharged on the fifty fifth day, quite well, having gained eight pounds in weight in the last three weeks, and having taken solid food for that period.
CAsE 5. - Sarah l'-_., aged fifty-nine, needlewoman. This was a severe case. The patient had had two attacks, with hromatemesis, in the previous ten years, for which she had been treated at this hospital. When arlmitted or June 14th, 1887, with a history of sudden and profuse hrematemesis and melsena on the 11 th, she was nearly dead. She was ordered enemata of two ounces and a half of strong beef-tea, half the yelk of an egg, and two ounces of brandy every four hours. On the tenth day she had two ounces of milk and half an ounce of brandy by the mouth alternately with the enemata; on the twelf th enemata every six hours, and two ounces of milk and two ounces of brandy by the mouth every three hours. Enemata were discon. tinued on the seventeenth day. On the thirty-fourth day she had solid food. She has remained well up to the present date.

CASE 6. -Sarah P_ was admitted to hospital on June 14th, 1887. This was a case of very marked symptoms of six weeks' standing, but with no hiematemesis. There was, as in all the other cases, severe localised epigastric tenderness. She had enemata of milk only every six hours and a similar quantity of milk by the mouth. On the fifteenth day the enemata were stopped, and she was dis. charged well (after taking solid food for ten days) on the thirty-seventh day.

CASE 7.-Josephine $\mathrm{O}_{-}$, aged twenty-five, cook, was admitted to hospital on Oct. $12 \mathrm{rh}, 1888$, an almost exactly similar case to the preceding. Enemata for nineteen days. Discharged well on the forty-second day.

CASE 8 - Elizabeth B-, aged twenty-three, cook, was admitted to hospital on (Ut. lst, 1889, with symptoms of ten days duration. The attack began with severe vomiting of blood, which was repeated on the day before admission. She was given a nutrient suppository every four hours, and in a few days enemata of milk and beef-tea (half an ounce of each) every hour. On the fifteenth day she had milks and beef-tea (of each one ounce) every hour, with an egg and a little bread-and-butter once in the day, and the enemata were discontinued. She had meat on the thirtietb dav, and was a month longer in hospital, quite well.

CASE 9.-Dinah $\mathrm{H} \longrightarrow$, aged thirty, was admitted to hospital on Nov. 29th, 1889. Pain for five months with vomiting, and hiematemesis (about half an ounce) every few days for tiwo months. She had had no meat for four munths. She had enemata of milk (two ounces) every three houss, and was free from pain ; but after three days, thougl the enemata were, as in all the other cases, well retained, she left the hospital, preferring her disease to the renedy.

CASE 10._Alice $\mathrm{C}$ - - aged twenty-three, waitress, was admitted to hospital on Nov. 13th, 1889. Very severe symptoms for two years, but no definite history of unmis. takable hrmatemesis. She had enemata of milk (two ounces) and beef-tea (one ounce) every four hours, with ice to suck, for nineteen days; and then had in addition two ounces and a half of milk every hour by the month. On the thirtieth day she left off the enemata, and on the thirty-fourth she had some solid food. There was occasional slight, pain for the first three weeks, but no vomiting. She was fifty-nine days in the hospital.

Remarks. - These patients all did well with fluid enemata, mostly untreated by any digestive agent. From an experience of many cases cther than those detailed, some of which I have treated with peptonised fluid enemata, some with simple fluid enemata, and a few with suppositories, 5 am confident that those who have the simple fluids, such $2 \mathrm{~g}$ milk, or milk and beef-tea, do every whit as well as the others. All the patients, whatever rectal alimentation they receive, waste more or less, some considerably, but theyrecover flesh as quickly. I will not discuss here the question as to whether the water of the enemata may not be the only valuable element. It is certainly striking that there is apparently no difference between the results of treated and untreated enemata, and as in a large majority of my cases I give absolutely nothing, not even jee, by the moath for many days, I always now use fluid enemata; deeming suppositories in such instances quite out of the question. Suppositories, moreover, are an unneceseary expense, though, doubtless, more convenient to the paient. I have never made the experiment of using injections of water alone, but I think it might justly be tried in the case of a patient not in a hospital. There is certuinly grave phvsiological doubt as to whether any albuminous substavces, however treated, are assimilated after rectal "feeding," and it has been amply demonstrated by fasting folk that man can live fos 
many days on water alone. A carcful series of weighings would be valuable in cases treated by different enemata; but I have not had this carried out systemat'cally in any case which I deemed it necessary to treat in this way, as I regard absolute rest of the body as an important aid to quick recovery. I have scarcely ever any trouble about the retention of enemata. They should never be larre, but may vary from two to three ounces as a rule, the frequency of repetition being decided in each individual casc. Success is largely due to the care of the nurse, who should give the injection slowly, and encourage the patient to help the operation. The rectum should be washed out when any irritative symptons appear, and opium will then seldom be necessary. To the sister of my ward for women, who for many years has superintended the treatment of these cases with every attention to detail, I owe much of the success I have had. The lesson to be dexived from consilleration of such cases as these is that there is no difficulty in keepincr most patients on fluid enemata for some weeks; that in all cases when the symptonis are masked, such treatment is imperatively demanded at once; that even in doubtful cases it is very often advisable, though very small and frequently repeated quantities of milk \&c. by the mouth may often be tried with success, and are thus obviously preferable; and that drug treatment of any kind is scarcely ever of any use, and would be, as a rule, contraindicated. After the resumption of solid food, nutrition is apparently aided by the administration of arsenic and iron for some time. Front time to time, and especially in cases which are fed by the mouth on milk throughout, evacuations of the lower bowel must be effected by means of simple enemata, and the rectum should never in any case be allowed to remain or become loaded.

In conclusion, I would remark that in my experience, both clinically and anatomically, gastric ulcer is immeasurably more frequent in women than men. This is the view of most anthorities, with the exception of Dr. Fagge, who quotes his experience in the post-mortem room of Guy's Hospital as not supporting the disproportionate distribution between the sexes. Domestic servants, and especially cooks, contribute largely to this class of cases, and I have been sometimes inclined to think that their habit of eating much and often hurriedly at all times and seasons, and just possibly their passion for unlimited vinegar, has something to do with the production of the malady; but Dr. Wills, who has made special inquiries regarding the first of these points, in many cases finds that this cannot be established as an invariable element of causation. That the well-to-do and generally healthy but seldoin suffer from gastric ulcer is, however, not to be questioned, and it is further certain that, whether it be regarded causally or not, considerable anxmia of long standing often precedes the symptoms of undoubted or demonstrated ulceration.

Harley-street, W.

\section{OBSERVATIONS ON THE ADMINISTRATION AND DANGERS OF AN ASTHETICS.}

BY JAMES DUNLOP, M.D.,

SURGEON TO THE ROYAL INIIRMARY, PROFESSOR OF SLRGERY AT ANDERSON'S COLLEGE, AND MEDICAI, EXAMINER IN CRIMINAL CASES, GLASGOW.

IN view of the recent development of this subject, circulars asking for information upon it have been issued by Tre LANCET to scientific medical men thoughout the world. This circular has stimulated Dr. Dunlop to record the results of his observations on the subject made in wards 15 , 23 , and 24 of the Glasgow Royal Infirmary during the last ten years, and to state his opinions thereupon.

Allowing for unrecorded cases in these wards, the following opinions are based on olsservations of 3500 cases within the specified period. To produce anasthesia in this number of patients, chloroform has been principally used. In the administration, the drop method was adopted. Ether was sometimes employed; its use by Clover's apparatus was begun on March 8th, 1882. Its use was greatly dependent on the skill and ability of the assistant, some assistants administering the drug with greater skill than others. In a general way ether was administered in the proportion of one case of ether to thirty cases of chloroform. Ether was employed preferably in cases of debility from long-standing disease of joints or from loss of blood in severe rail way smashes or machinery injuries. This drug, however, was found unsuilable in operations for hernia, lithotomy, reduction of dislocations, rectal operations, and in persons suffering from pulmonary or bronchitic ailments, or addicted to habits of intemperance. lieferring $x$ to the relative dangers of various anasthetics at the operation or after the operation, Dr. Dunlop remarks that "chloroform is never absolutely safe, no matter how carefully or how skilfully it might be administered. Chloroform is much more dangerous than ether during operations; but after operations ether is more dangerous to life than chloroform from bronchitis or pneumonia setting in. It may be said that when pneumonia or bronchitis follows, the ether was badly administered. That may have been so. It is much more difficult to administer ether accurately than to administer chloroform accurately." On two occasions recently he encountered great difliculty with ether. In c ne case the breathing had almost ceased, and the pulse failed. The young woman's face had become blanched. She was dying not from asphyxia, but from weak heart action. The remainder of Dr. Dunlop's remarks are as follows :-

Every intelligent assistant I have had during the last ten years has felt happier during an operation when ether was used than when chloroform was administered. I have not seen any deaths from ether or chloroform for ten years; but I have seen many patients both in hospital and in private practice in very imminent danger to life during the administration of chloroform, the symptoms in some instances being those of impending asphyxia, in others those of defective heart action. I have laid down for my own guidance as a surgeon the rule never to have chloroform administered to a patient in my own house, even by the patient's own medical man. It is an extremely awkward and painful experience for a surgeon to have a death from chloroform in his own consulting-roum.

A patient coming from the country, accompanied by the family doctor to administer chloroform in a surgeon's consulting-room, the patient to have an examination for stone, or the excision of a wen, or a reduction of dislocation at the elbow, or the breaking down of joint adhesions, is usually in a very unfavourable and unsafe condition for chloroforming. The patient is probably hot, anxious, excited, nervous, and tightly clothed, and at an early stage of the administration of the anæsthetic by the family doctor sym. ptoms of heart danger suddenly appear, and death ensues. It is really much safer for such a patient's life to have him rest for a time in a hotel or elsewhere, and to have the anæesthetic adninistered there rather than in the surgeon's house. Under no circumstances, and for many reasons, should chloroform be administered by a medical man with. out at least a third party being present. Again, I never now administer chloroform in a dentist's room in dental cases. There is always great danger to life, and deatbs have been far too numerous in the rooms of dentiats. Besides, nitrous oxide is so much safer in the hands of dentists than chloroform.

In the space at my disposal it is not my intention to diecuss the general accuracy of what is termed Syme's views on the administration of chloroform, or to consider the conclusions arrived at by the Hyderabad Commission, which are based on experiments performed on Indian dogs and monkeys. To help THE LANCET in its consideration of the question, How to save people's lives? I desire to contribute some evidence on the other question, Why and how do some people die under the influence of chloroform ?

During the last twenty years in conjunction with my colleague, Dr. Moore, as one of the medico-legal examiners for the city of Glasgow, I have had exceptionally favourable opportunities of acquiring experience of the fatal results following chloroform administration. In these years there has been a considerable number of deaths of individnals while under the lnfluence of chloroform. The deaths, which were made the subject of post-mortem examination, took place in the Royal and Western Infirmaries, in the hospital of the Barnhill Poorhouse, in the operating rooms of dentists and consulting-rooms and elsewhere of private practitioners in the city and suburbs of Glasgow, within the county of Lanark. A careful study of such details as are before me leads me to the conclusion that considering the population, its numbers and character under medical trestment, and subiected to chloroform, the proportion of fatal cases is very small, probably not more than from two and a half to three rer annum. Within the last ten years the 